\title{
LINKING AGENT-BASED COMPUTATIONAL ECONOMICS TO POST KEYNESIAN ECONOMICS*
}

\author{
Assoc. Prof., M. Oğuz ARSLAN \\ Anadolu University, Faculty of Economics and Administrative Sciences, Eskişehir, Turkey (moarslan@anadolu.edu.tr)
}

\begin{abstract}
Agent-based computational economics is relatively a new methodology in economics. It is defined as 'the computational modeling of economic processes (including whole economies) as open-ended dynamic systems of interacting agents'. Contrary to fundamental assumptions of neoclassical and mainstream approaches, agent-based computational economics assumes that (a) agents are heterogeneous and bounded rational decision makers in an economy, (b) an economy is a non-linear, complex and adaptive system. Moreover, these assumptions seem to hold true for Post Keynesian economics to a large extent. Given that, this study attempts to bring out similarities and potential links between these two economic thoughts.
\end{abstract}

Keywords: Economic Methodology, Post Keynesian Economics, Agent-based Computational Economics.

\section{AJAN TABANLI HESAPLAMALI İKTISATI POST KEYNESYEN IKTISATLA BAĞLANTILANDIRMAK}

\section{ÖZET}

Ajan tabanl hesaplamall iktisat, iktisat içerisinde nispeten yeni bir metodolojidir. Bu metodoloji ekonomik süreçlerin, ekonomik ajanların açık uçlu dinamik sistemleri olarak hesaplamalı modellemesi şeklinde tanımlanır. Neoklasik ve ana akım yaklaşımların temel varsayımlarının aksine, ajan tabanlı hesaplamalı iktisat; (a) ekonomide ajanların heterojen ve sinırlı rasyonel karar alıcılar olduğunu ve (b) ekonominin doğrusal olmayan, karmaşı ve uyumlu bir sistem olduğunu varsaymaktadır. Ayrıca, bu varsayımlar Post Keynesyen iktisat için de büyük ölçüde geçerli görünmektedir. Bu çerçevede, bu çalışma bu iki ekonomik düşünce arasındaki benzerlikleri ve potansiyel bağlantıları ortaya çıkarmayı amaçlamaktadır.

Anahtar Kelimeler: Ekonomik Metodoloji, Post Keynesyen İktisat, Ajan Tabanlı Hesaplamalı Iktisat.

* This study was presented at EconWorld 2016 Conference in February 1-3, 2016 in Barcelona, Spain. 


\section{Introduction}

Agent-based computational economics (hereafter, ACE) is a newly developed methodology in economics. It is agent-based modeling (hereafter, ABM) that give rise to the development of ACE as a type of heterodox school of economic thought. Contrary to fundamental assumptions of neoclassical and mainstream approaches, ACE assumes that (a) agents are heterogeneous and bounded rational decision makers in an economy, (b) an economy is a non-linear, complex and adaptive system. Additionally, these assumptions seem to hold true for Post Keynesian economics (hereafter, PKE) to a large extent. In this context, this paper attempts to bring out similarities and potential links between these two economic thoughts.

This paper has four more sections. The next section briefly presents ABM methodology. The third one explains ACE as a new school of thought in economics. The fourth section presents similarities and potential links between ACE and PKE. The last section concludes the study.

\section{ABM}

Equation-based modeling is being used in nearly all fields of sciences and also has become dominant modeling methodology for a long time. However, as a relatively new methodology, $\mathrm{ABM}$ has been challenging this methodology with its distinctive computational and complexity power for some time. Complexity Explorer website of The Santa Fe Institute defines an agent-based model as:

"A computational simulation in which the individual components ("agents") of a system are represented and interact explicitly. An agent-based model is typically iterated over time steps, with aspects of the agents updated at each time step. Agent-based models (hereafter, ABMs) can be contrasted with models in which the behavior of the system is based on equations and individuals are not represented explicitly" (Complexity Explorer).

The history of ABM in social sciences dates back to the 1940s. Though there were early examples of ABM in that years, the initial developments happened in parallel with the first use of computers in university research centers in the early 1960s (Gilbert \& Troitzsch 2004).

The cornerstone of the development of ABM in the social sciences is Thomas Schelling's cellular automaton-type racial segregation model (1971) that simulates observed racial segregation in US cities at that time. Briefly, Schelling's racial segregation model asserts that segregation of groups and communities is possible even if individuals are tolerant of living among different kind of agents (Janssen 2013). Figure 2 below shows the implementation of Schelling's racial segregation model on the most popular agent-based modeling platform NetLogo (Wilensky 1997; 1999). 
Uluslararası Yönetim İktisat ve İşletme Dergisi, Cilt 13, Sayı 1, 2017, ss. 1-17 Int. Journal of Management Economics and Business, Vol. 13, No. 1, 2017, pp. 1-17

Figure 1: The development of ABM in the social sciences

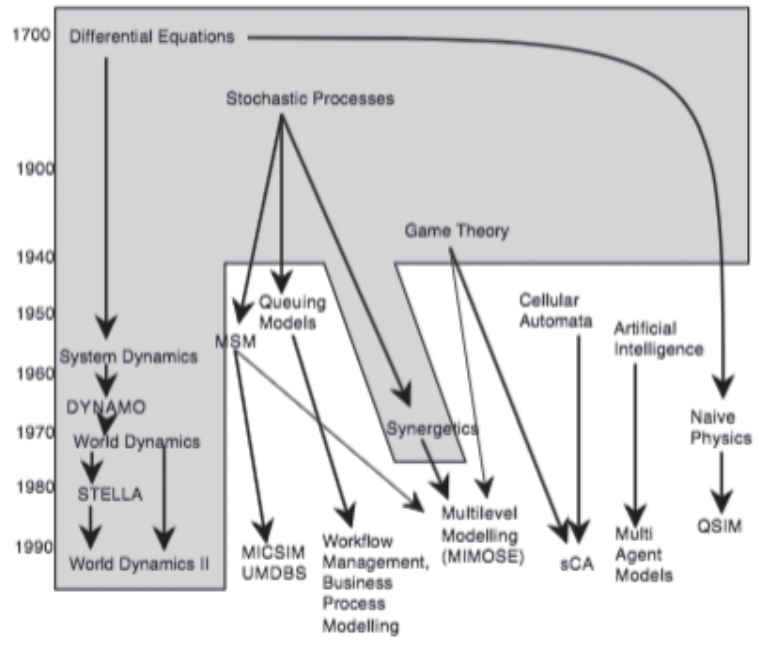

Source: Gilbert and Troitzsch (2004).

*Grey colored area represents equation based models; white colored area represents event, object or ABMs.

Figure 2: A Snapshot of Netlogo Implementation of Segregation Model

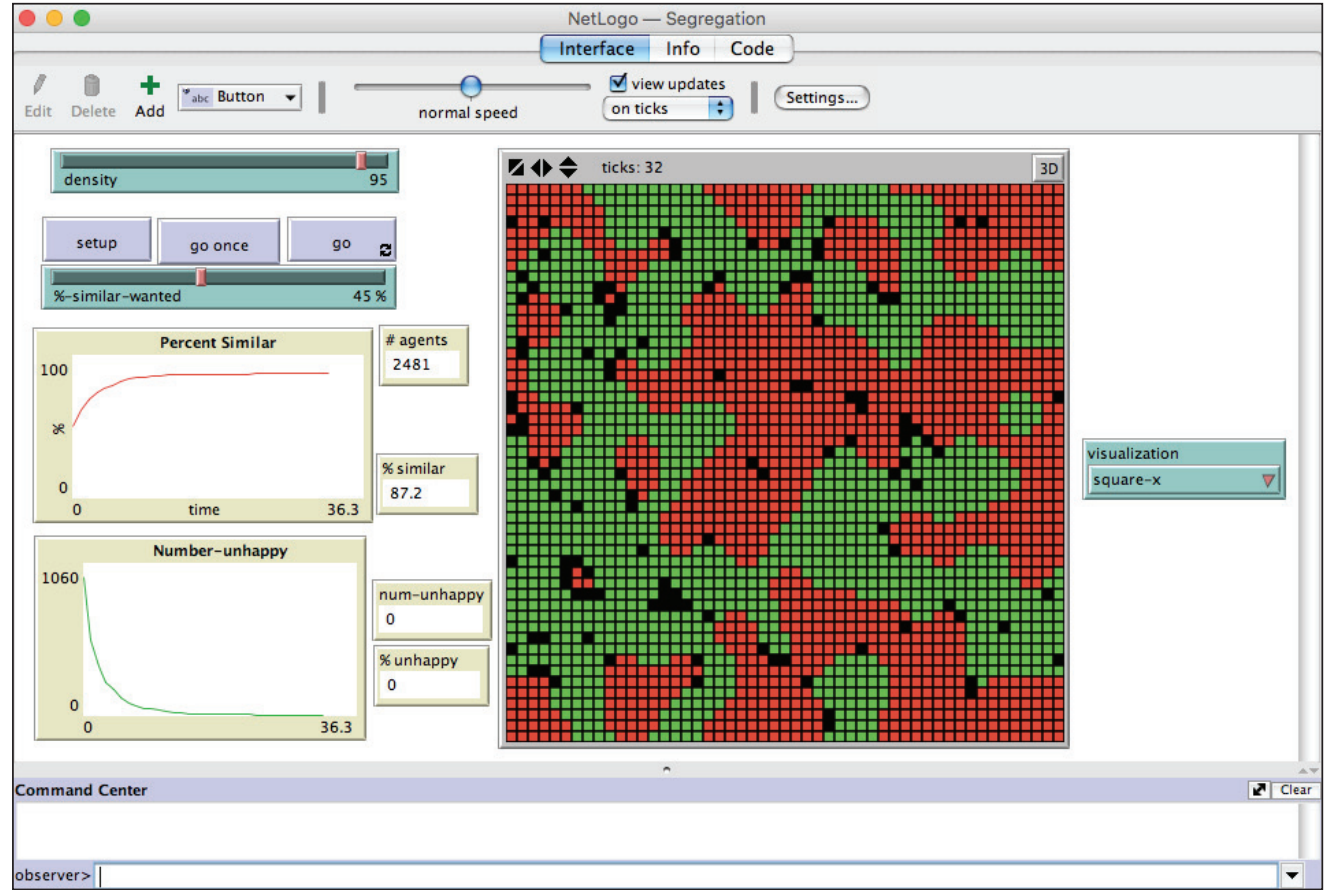


In this model, red and green agents (individuals) are placed on empty patches (places) randomly. The main idea behind the model is that agents are happy to stay in the patch which they are in if at least a proportion. An agent has eight neighbors (Moore neighborhood in math) and \%-similar-wanted of the agents in the eight surrounding patches are of the same color. Accordingly, the agents still tolerate agents of other color, but may not wish to be completely parted from their own color. If an agent feels not happy, it will move to a neighbor patch randomly. At first, the agents placed on the patches randomly. All agents evaluate their situation in a random order in every tick (time step) and the model run stops when all agents feel happy (Janssen 2012). This model depicts how these agent preferences ripple through the neighborhood, leading to a large-scale pattern (Wilensky 1997).

This model has produced a surprising result that agents who tolerate diversity begins to become segregated. For example, with a $45 \%$-similar-wanted value at the beginning, the model produced the result that $87.2 \%$ of the neighbors of agents have the same color. This result reveals that segregation is possible without any planned and intended discrimination of certain agent types (Janssen 2012).

However, the surprising results that are generally produced by ABM are not proof that actual physical, biological and social phenomenon happens in such a way. But they may help to explain these phenomenon and also natural and social systems more accurately due to the characteristic features of ABM. ABM has following main features (Epstein 2006a; Gilbert 2008; Complexity Explorer):

- Heterogeneity: Representative agents are not used in ABM. Also, agents are not aggregated into a few homogeneous pools. Instead, agents are heterogeneous that means agents may differ in genetically, culturally, by social network, by preferences etc. all of which may change or adapt internally over time.

- Autonomy: In ABM, there is no central or 'top-down' control over agents' behavior. On the contrary, collective behavior of agents is formed in a decentralized or 'bottom-up' way. This feature sometimes leads to emergent behavior of the system.

- Local interaction: The interaction between agents is simulated locally in ABM. This interaction can consist of transferring data from an agent to another agent.

- Bounded rationality: ABM assumes that agents are boundedly rational. It means that they are limited in the amount of cognitive processing in which they can engage in decision making. According to Epstein (2006b), it has two components: bounded information and bounded computing power.

- Adaptivity: In ABM, the term 'adaptive' implies to interacting agents that singularly or collectively are able to respond to environmental changes.

- Learning: ABMs are able to simulate learning at both the agent and group levels.

- Non-equilibrium dynamics: This feature consists of important concepts such as 'largescale phase transitions', 'tipping point phenomenon', and 'emergence' ('the whole is greater than the sum of its parts') that are different from equilibrium existence theories.

- Non-linearity: ABMs generally show non-linear effects in which the global behavior of the model can become path-dependent and self-reinforcing, producing high sensitivity to initial conditions (David 2013). 
Finally, we can add another feature for ABM: Eligibility for complexity science. ABM is one of the most eligible methodology and tool for modeling complex, non-linear and chaotic events and systems successfully because of its computational power as well as characteristic features given above.

\section{ACE}

The application of ABM to economics is named as ACE. One of the leading economists in the field and the father of the term ACE, Leigh Tesfatsion of Iowa State University, has defined ACE as, "the computational study of economic processes modeled as dynamic systems of interacting agents" (Tesfatsion 2006). The development of ACE is closely linked with studies done at the Santa Fe Institute in US (Richiardi 2012).

Agent types in ACE include individuals (e.g. city resident, family farmer), social groups (e.g. families, communities), institutions (e.g. corporations, markets), biological entities (e.g. crop, livestock), and physical entities (e.g. weather, river). In ACE models too, agents are encapsulated software actors who capable of adaptation to environmental conditions, social communication with other agents, goal-directed anticipatory learning and autonomy. ACE models provide users an opportunity to explore the effects of structural conditions, institutional arrangements, and human decisions on system outcomes over time (Tesfatsion 2016).

Figure 3: ACE triangle

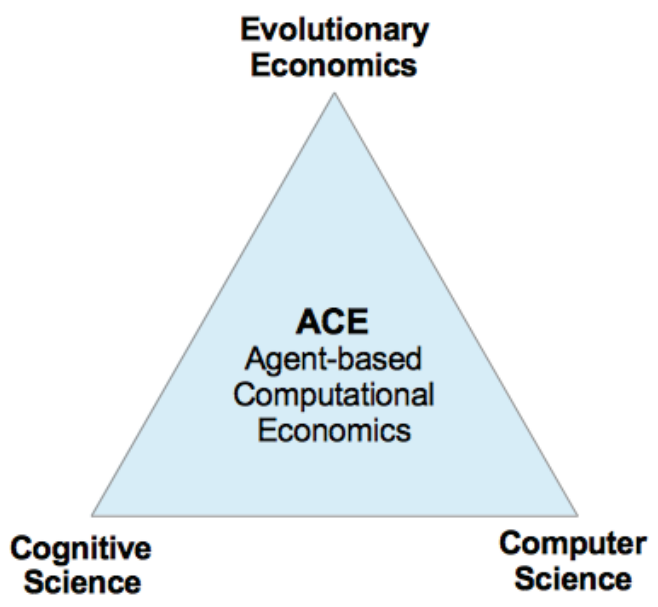

Source: Tesfatsion 2016.

Tesfatsion has put ACE approach in an equilateral triangle (ACE triangle) that has sides as 'evolutionary economics', 'cognitive science' and 'computer science' as seen in Figure 3. This triangle shows that in ACE approach: 
- agents are evolving like species in evolutionary biology,

- agents' cognition regarding intelligence and behavior is important,

- computational power is needed for simulation and calculation in ACE models.

According to Tesfatsion (2016), there are four main strands of ACE research. These are:

- Empirical understanding: Aims to produce possible reasons for observed regularities in the absence of any central authority.

- Normative understanding: Aims to make good market design in addition to fiscal and monetary policy design.

- Qualitative insight and theory generation: Aims to gain a better understanding of dynamic economic systems. e.g. to understand self-organizations of decentralized markets.

- Methodological advancement: Aims to provide methods and tools for ACE researchers for undertaking theoretical studies.

\section{1. The Relations With Neoclassical and Mainstream Economics Approaches}

By some views, ACE has been thought as a part of or compatible with neoclassical and mainstream economics approaches especially due to its microeconomics content (e.g. concept of agent). It is claimed that, at least, ACE models do not represent any sort of rejection of neoclassical economics and the latter is able to absorb the Santa Fe Institute-type advances without changing its fundamental property (Blume and Durlauf 2006). Moss (2011) accepts microeconomics basis of ACE but criticizes neoclassical economics to be incompatible in principle with complexity. Moss also shows some strands in the economics and social sciences literatures to construct macro analyzes explicitly on micro foundations. The main strands are computable general equilibrium (CGE), ACE, agent-based social simulation (ABSS) and complexity science (CS) including econophysics and sociophysics. According to Moss, they are not all mutually exclusive although there are some conflicting elements among several of them.

The interdisciplinary feature of ACE is depicted by Reid (2014) as seen below. Reid (2014) puts ACE in the intersection set of mainstream economics, computational intelligence, and cognitive psychology and asserts that because these models do not rely upon aggregated historically observed trends, they could be used to understand the results of economic policies set by governments and business.

\section{2. ACE as a Heterodox Approach}

Although ACE has a microeconomics content to some extent, it can be labeled as a heterodox approach because of its inconsistencies with neoclassical and mainstream economics approaches with regard to heterogeneity, autonomy and bounded rationality of agents, and nonequilibrium dynamics view of ACE. For example, Lavoie (2015) qualifies ABM (hence ACE) as one of the heterodox schools of thought in economics, of which there are several famous schools such as PKE, radical economics, Schumpeterian economics and behavioral economics. 
Figure 4: The main strands in the economics and social sciences literatures

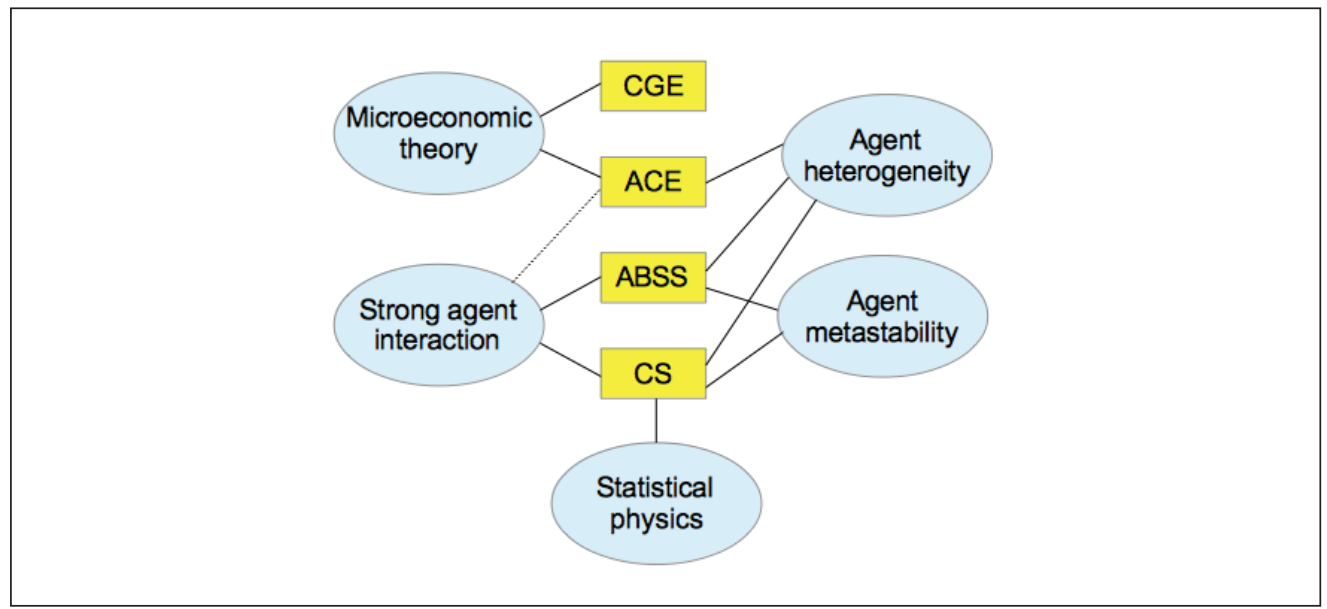

Source: Moss (2011).

Figure 5: The interdisciplinary feature of ACE



Source: Reid (2014).

One of the main differences between neoclassical/mainstream economics and ABM/ $\mathrm{ACE}$ is, of course, the diversity of agents. In neoclassical economics, agents are representative and homogeneous entities to enable and to facilitate rigor mathematical abstraction in economic models. Hence, neoclassical economic models are run off perfectly in a mechanistic way with 
ease, theoretically. However, in agent-based approaches, agents are heterogeneous entities that (a) are modeled individually and (b) use inductive rules of thumb to make decisions.

Agents are also autonomous entities in agent-based approaches which means there is no central or 'top down' control over agents' behaviors and collective behavior of agents is formed in a 'bottom-up' way. The consequence of this process - together with interactions among agents and between agents and environments - sometimes yields to 'emergence' phenomenon. A quotation from Aristotale entirely suits this phenomenon: "the whole is greater than the sum of its parts". Hence, macro patterns are emergent results of micro level behaviors and interactions and there is no difference between microeconomics and macroeconomics in agentbased approaches, though microeconomics and macroeconomics remain different parts in neoclassical/mainstream economics (adapted from Thornton 2014).

Another difference between these approaches is about rationality of agents. In neoclassical/mainstream tradition, agents are perfectly rational entities and make their decisions under complete information. Also, they do not make mistake systemically and do not repeat the same mistake. Conversely, in ABM/ACE approach, agents are bounded rational entities and they make their decisions under incomplete information. To Epstein (2006b),

"There are two components of this [bounded rationality]: bounded information and bounded computing power. Agents have neither global information nor infinite computational capacity. Although they are typically purposive, they are not global optimizers; they use simple rules based on local information".

ACE is also diametrically opposite to neoclassical/mainstream economics regarding equilibrium notion. Although neoclassical/mainstream economics theory has completely based on equilibrium notion, e.g. dynamic stochastic general equilibrium (DSGE), ACE approach has accepted non-equilibrium dynamics or out-of-equilibrium approach. W. Brian Arthur states this difference elegantly:

“Standard neoclassical economics asks what agents' actions, strategies, or expectations are in equilibrium with (consistent with) the outcome or pattern these behaviors aggregately create. Agent-based computational economics enables us to ask a wider question: how agents' actions, strategies or expectations might react to-might endogenously change with-the pattern they create. In other words, it enables us to examine how the economy behaves out of equilibrium, when it is not at a steady state.

This out-of-equilibrium approach is not a minor adjunct to standard economic theory; it is economics done in a more general way. [...] The static equilibrium approach suffers two characteristic indeterminacies: it cannot easily resolve among multiple equilibria; nor can it easily model individuals' choices of expectations. Both problems are ones of formation (of an equilibrium and of an 'ecology' of expectations, respectively), and when analyzed in formation-that is, out of equilibrium-these anomalies disappear” (Arthur 2006).

In this respect, Basil Moore envisages the future of equilibrium notion in vigorously manner in his sentences as: 
"Sooner rather than later, economists will recognize "equilibrium" is useless and misleading. They will stop postulating and solving for "equilibrium" configurations. Economies are non-linear, and "shocks" are endogenous and continual in their effects. Economic variables have unit roots in levels and not deterministic trends. Most economic distributions are fractal, have a memory and may be characterized as non-periodic. There are no constant "systematic" factors in economics like the planets, whose behavior may be captured and measured with statistical confidence. In economies nothing can be truly known in advance. Economies have no underlying "structure" and no unique "future" that can be discovered. Contingency is fundamental. In complex adaptive systems things happen ... Just happen” (Moore 2006).

In ACE approach, the economy is also an adaptive system. This adaptivity exists on two levels: the economic system may be capable of adapting to external factors without agents being aware of this adaptation which is happening, and agents may be capable of adapting to the economic system (Bruun 2007). On the other hand, neoclassical/mainstream approaches accept the economy substantially as a static system.

Non-linearity is one of the basic properties of ABM/ACE approaches too. While neoclassical/mainstream approaches evaluate the economy as a linear system, ACE views the economy as a non-linear system with many degrees of freedom that is inherently chaotic, displaying random fluctuations and major instabilities (dramatically exemplified by the Global Financial Crisis of 2008) (Hasselman 2010).

In summary, all of these disagreements with neoclassical/mainstream economics give ACE approach a strong heterodox character, though ACE has been founded on standard microeconomic theory to some degree. This leads to a widely acceptance of ACE as a heterodox school of economic thought or at least a heterodoxy-friendly school of economic thought although there are a few disagreements. Hence, Lee (2012) interprets heterodox economists' thought on these issues as follows:

"Since the entire theoretical corpus of neoclassical economics is false knowledge, it is not clear why heterodox economists should pay attention to the mainstream frontier advances. Yet, in contrast to the assertions by the critics, heterodox economists do engage with past and current mainstream literature, including the cutting-edge research. Their critical analysis of the frontier research identified by the critics as classical-evolutionary-behavioral game theory, evolutionary-behavioral-experimental economics, neuroeconomics and agent-based complexity economics indicates that as a whole these research programs are too solidly rooted in neoclassical theory to escape being false knowledge".

\section{3. A sample ACE model in NetLogo: Simple Economy Model}

This model is a very simple model of economic exchange that provides a ground-up simulation of inequality in wealth. It is a thought experiment of a world where, in every time step, each person gives one dollar to one other person (at random) if they have any money to give. If they have no money, then they do not give out any money. In the model simulation, the SETUP for the model creates 500 agents, and then gives them each 100 dollars. At each tick, they give one dollar to another agent if they can. If they have no money, then they do nothing. Each agent also moves to an x-coordinate equal to its wealth (Wilensky 2011). 
Figure 6: A snapshot of NetLogo implementation of Simple Economy model

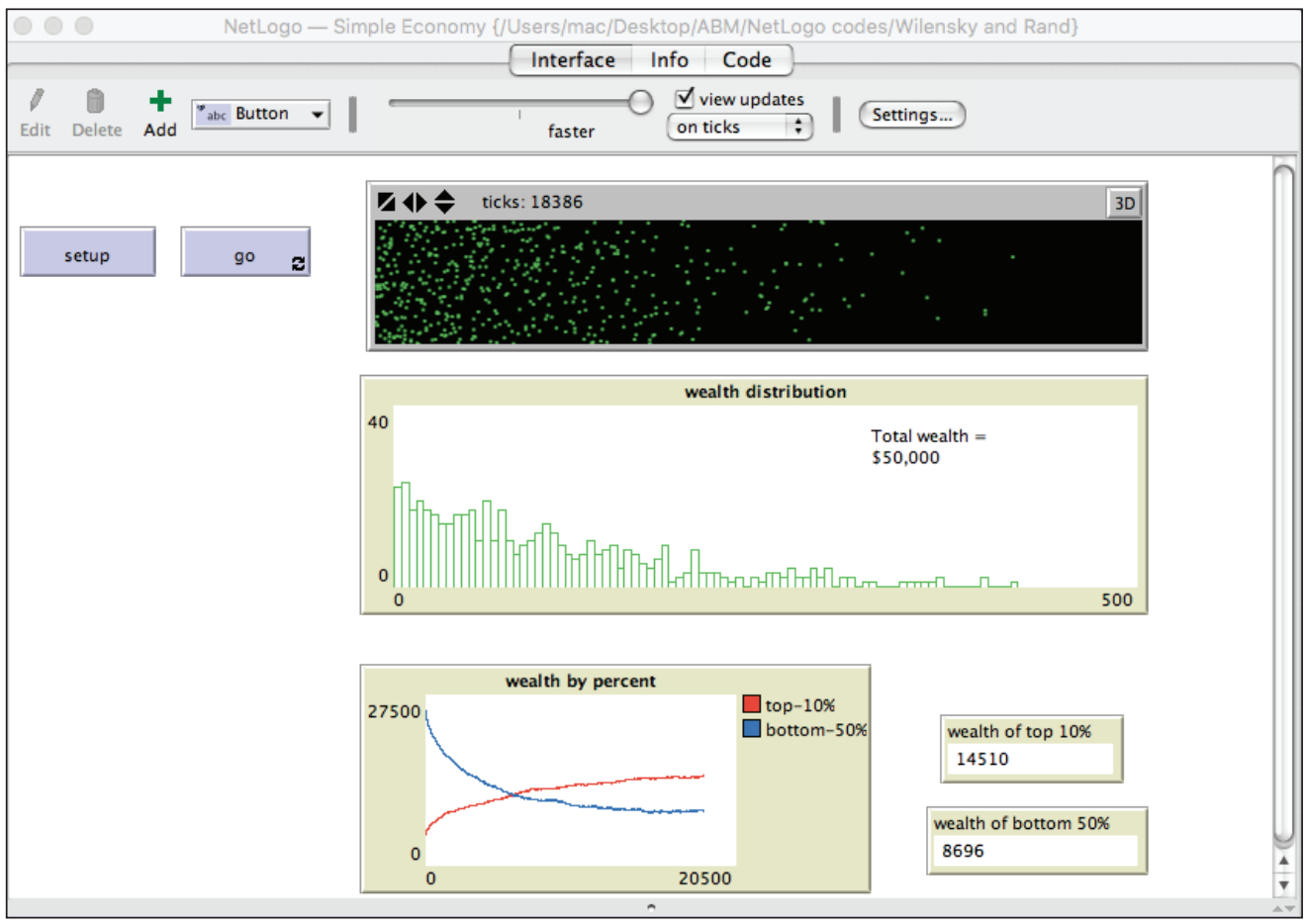

Simple Economy model explores whether all the wealth will be equitably distributed or will be concentrated in a few agents, under the conditions that no agents starts off with an advantage and the selection of agents to whom money is transferred is random. Thus, for many people, the resulting wealth distribution should be relatively flat. Surprisingly, the result of the model run indicates that wealth distribution becomes unequal after a while (Wilensky and Rand 2015).

\section{The Similarities and Potential Links Between ACE and PKE}

ACE has some similarities and potential links with schools of heterodox economics since diverse schools and approaches in heterodox economics (e.g. Classical-Marxian, Post Keynesian, Austrian, Institutionalist) tends to share one common theoretical base that 'economic outcomes are predominantly determined by the relations between socioeconomic structures and the agents who inhabit it' (Cogliano and Jiang 2016).

By all means, PKE is one of the most appropriate heterodox school of economics to establish a partnership with ACE although there is a controversy between Davidson and other Post Keynesians (e. g. Rosser, Moore) on this issue. It is stated that as a theoretical approach that draws upon the work of Keynes, Kalecki, Robinson, Kaldor, Kahn and Sraffa, PKE is distinguished by the central role of the principle of effective demand (that demand matters 
in the long run) and an insistence that history, social structure and institutional practice be embodied in its theory and reflected in its policy recommendations" (The Post-Keynesian Economics Study Group). Especially, the relation between socioeconomic structure and agents is standing on the center of PKE. As Cogliano \& Jiang (2016) noted,

"The capitalist structure of production and distribution determines the behaviors of economic agents in the system, and a set of macroeconomic phenomena (e.g. inflation, unemployment, cycles and fluctuations, etc.) emerge out of the interactions amongst those agents as unintended consequences".

Cogliano \& Jiang (2016) also emphasize the importance of heterogeneity of agents for PKE,

"(T)he heterogeneity of agents and high flexibility in agent construction make ABM an extremely useful methodology for some important Post Keynesian research programs involving the explorations of emergent macroeconomic properties, unintended consequences, and the fallacy of composition".

Moreover, it is maintained that $\mathrm{ABM} / \mathrm{ACE}$ may be preferred by Keynesian/PKE approaches based on the idea that "the macro economy is best understood as one populated by many heterogeneous, interacting, "simple" agents giving rise to a complex adaptive system ${ }^{1}$. It is asserted, too, due to advances in computational theories and applications, ABM methodology have had a rigorous and reliable platform to deal with the threatening constructive and interpretative problems posed by complex adaptive systems. Second, ABM allows to overcome the difficulties encountered at Keynes's time and after until very recently in translating his ideas into a computable, quantitative model (Canzian et al. 2009).

One of the fundamental assumptions of Keynesian/Post Keynesian approaches is uncertainty of the future. In that sense, complex dynamics ${ }^{2}$, hence ACE, enter into the analysis of Keynesian uncertainty in at least two ways. The first way is the very existence of chaotic dynamics in an economic system. If an economic system exhibits chaotic dynamics, it is subject to sensitive dependence on initial conditions, probably the most important defining characteristic feature of chaotic dynamics which also reflects non-linearity of the system (Rosser 2006),

"A system's sensitivity to initial conditions refers to the role that the starting configuration of that system plays in determining the subsequent states of that system. When this sensitivity is high, slight changes to starting conditions will lead to significantly different conditions in the future. Sensitive dependence on initial conditions is a defining property of chaos in dynamical systems theory" (Complexity Explorer).

1 A complex adaptive system is a "complex macroscopic collection" of relatively "similar and partially connected micro-structures" formed in order to adapt to the changing environment and increase its survivability as a macrostructure (Wikipedia(a)).

2 Complex dynamics is the study of dynamical systems defined by iteration of functions on complex number spaces (Wikipedia(b)) 
The second way is the possibility of fractal basin boundaries. According to Rosser (2006),

"With fractal basin boundaries there are multiple equilibria, and the basins of attraction for each of the equilibria are entwined with each other so that their boundaries may become arbitrarily close to each other. There may not be chaotic dynamics, but the system can jump discontinuously from one basin of attraction to another from nearly infinitesimal changes, thus rendering the possibility of forming rational expectations impossible”.

Beyond uncertainty notion, a crucial commonality between ACE and PKE is system dynamics. As Radzicki (2008) points out, 'it is a dynamic, disequilibrium approach to modeling complex systems that portrays human behavior and micro-level decision making as it actually is rather than as it might be in an idealized state. To a system dynamicist, the macro behavior of a system is caused by its micro structure'. To Radzicki (2008), complex/system dynamicists 'view the world through the same lens' as Post Keynesian and Institutionalist economists, and there are certainly strict links between the feedback loops and the stock-flow analysis promoted by complex/system dynamicists and the stock-flow coherent analysis suggested by some Post Keynesian economists.

Richard M. Goodwin's studies between 1940s and 1960s are probably the most influential works on this issue. Among them, Goodwin's (1967) model of business cycles is of special importance. This model more explicitly drew on ecological predecessors in the form of the predator-prey model of Lotka and Volterra. It is the workers with their wage demands who play the role of the 'predators', with their wage demands bringing about the reversal of the investment-driven capitalist expansion in Goodwin's model (Rosser 2009).

Goodwin (1967) has stated that 'Volterra's problem of the symbiosis of two populations -partly complementary, partly hostile- is helpful in the understanding of the the dynamical contradictions of capitalism, especially when stated in a more or less Marxian form'. Goodwin's model of business cycles is given by the following, where $W=$ wages. $Y=$ national GDP, with $W / Y=\omega$, the workers' share, $L=$ employed workers, $N=$ population of labor force, hence $L / N=$ the rate of employment, which is given by $\lambda$, with $P(\lambda)$ being a linear Phillips curve relation between the rate of employment and the rate of changes of wages, $K=$ the capital stock, $v=K / Y$, the accelerator relation, $\alpha$ is the rate of technological change, and $\beta$ is the rate of population growth. From all of these the model can be given as (Rosser 2009),

$$
\begin{aligned}
& d \omega / d t=\omega[P(\lambda)-\alpha] \\
& d \lambda / d t=\lambda[(1-\omega) / v-\alpha-\beta]
\end{aligned}
$$

In this regard, the predator-prey model of Lotka and Volterra deserves a closer look for understanding the Goodwin model correctly. For this aim, NetLogo Wolf Sheep Predation model may be used. Wolf Sheep Predation model is a model of a simple predator-prey ecosystem and uses the system dynamics modeler to implement the Lotka-Volterra equations. 
These equations are a pair of first order, non-linear, differential equations that describe the dynamics of biological systems in which two species interact (Wilensky 2005).

However, the system dynamics approach deals with an aggregate of individual agents, rather than with individual agents when it is compared with the characteristic features of $\mathrm{ABM} /$ ACE approaches. Hence, this makes it difficult to model heterogeneity among agents. Also, it is hard to represent agents' behaviors which based on past experiences, memories and learning abilities of agents in a system (Gilbert 2008).

One of the main areas which can help us to establish a strong link between ACE and PKE is the Global Financial Crisis of 2008. The failure of mainstream DSGE-based macroeconomics in predicting the advent of the Global Financial Crisis of 2008 has given a chance to ABM/ACE for economic-policy making, although predicting also seems difficult in ABM/ACE because of the inherent non-linearities implied by the complex interactions among heterogeneous agents. To rise to this challenge, some techniques such as 'maximum entropy' are applied to predict ABMs results (Gaffard and Napoletano 2012).

In 2010, a promising workshop was organized by Doyne Farmer and Robert Axtell to discuss viability of ACE as an alternative methodology to mainstream economics. At this workshop, the very potential of ACE to assist learning the lessons of the Crisis of 2008 and to develop an early-warning system for the future crises were explored. At this workshop, Andrew Lo presented a model of US housing market using ABM methodology which shows how rising housing prices, falling interest rates and easy access to refinancing tools created a fearful debt burden. Also some other studies modeled the Crisis of 2008 by using ABM. For example, John Geanakoplos explained how the debt cycle in remortgaging housing market create instability and Sujit Kapadia modeled the web of interdependencies generated by using complex derivatives (The Economist 2010).

It is very clear that ABM methodology and simulations can strengthen and give advice to policy makers and economists as those are informing many scientists in many fields of science. As once physicist Mark Buchanan puts out in an article in New York Times, 'this economy does not compute' and need computer simulation techniques (Buchanan 2008). Buchanan concludes his article as follows:

"If we're really going to avoid crises, we're going to need something more imaginative, starting with a more open-minded attitude to how science can help us understand how markets really work. Done properly, computer simulation represents a kind of "telescope for the mind," multiplying human powers of analysis and insight just as a telescope does our powers of vision. With simulations, we can discover relationships that the unaided human mind, or even the human mind aided with the best mathematical analysis, would never grasp.

Better market models alone will not prevent crises, but they may give regulators better ways for assessing market dynamics, and more important, techniques for detecting early signs of trouble. Economic tradition, of all things, shouldn't be allowed to inhibit economic progress." 
Besides, the complex and computational nature of ABMs make them more useful tools for analyzing financial economy realistically, especially in Keynesian/Post Keynesian sense. As Farmer and Foley (2009) emphasize very correctly,

"Agent-based models potentially present a way to model the financial economy as a complex system, as Keynes attempted to do, while taking human adaptation and learning into account, as Lucas advocated. Such models allow for the creation of a kind of virtual universe, in which many players can act in complex - and realistic-ways. In some other areas of science, such as epidemiology or traffic control, agent-based models already help policy-making”.

Methodologically, ACE seems to be a promising approach for PKE as regard its heterodox topics and anti-mainstream character. In this context, the fundamental assumptions of $\mathrm{ABM} / \mathrm{ACE}$ approaches as heterogeneity, autonomy, bounded rationality and adaptivity of agents; non-equilibria and non-linearity of systems conform to assumptions of PKE to a large extent. In addition to these methodological similarities, ABM/ACE allow to overcome the difficulties encountered at Keynes's time and after until very recently in translating his ideas into a computable, quantitative model and this is welcomed by PKE as a core Keynesian approach.

Those potential links between ACE and Keynesian/Post Keynesian thought have been realized in some recent studies, hence, a new literature on this issue has been emerging. For example, Bruun (2008, 2010), Bruun \& Heyn-Johnsen (2009), Setterfield \& Budd (2011), Michell (2014), Bassi \& Lang (2016) construct and simulate ABMs to explain some economic and financial matter of facts (e.g. growth, business cycles) from Keynesian/Post Keynesian point of view. When we take into account the increasing use of ABM methodology in many fields of science, the future direction of ACE-PKE relations seems very promising for explaining economic relations and economic systems in the real world.

\section{Conclusion}

ABM can be defined as "(computational) modeling of a heterogeneous population of agents and their interactions explicitly". These agents can represent individuals, households, firms, countries, etc. and have some characteristics such as heterogeneity, autonomy, local interaction, bounded rationality, adaptivity. In ABM, also, non-equilibrium dynamics and non-linearity are accepted as basic properties of a system. Hence, ABM is in contrast with equation-based modeling paradigm that is dominant modeling methodology in nearly all fields of sciences for a long time.

In this context, the application of ABM to economics is named as ACE. ACE seems to be a promising approach for PKE as regard its heterodox and anti-mainstream character as a new methodology in economics. Especially, the basic assumptions of ABM/ACE approaches (e.g. heterogeneity and bounded rationality of agents; non-equilibria and non-linearity of systems) seemingly conform to assumptions of PKE to a large extent. Moreover, ABM/ACE allow to overcome the difficulties in translating Keynes' ideas into a computable, quantitative model. Of course, this kind of opportunity may help Post Keynesian thought in particular, to have a useful and realistic methodology for analyzing today's complex economies. Some 
recent Post Keynesian studies can be accepted a sign of Post Keynesians'sympathy on ABM/ ACE methodology.

\section{References}

Arthur, W. B. (2006). Out-of-equilibrium economics and agent-based modeling. In Tesfatsion L. \& Judd K. L. (eds), Handbook of computational economics, 2: Agent-based computational economics (pp. 1551-1564). Amsterdam: North-Holland.

Bassi, F. \& Lang, D. (2016). Investment hysteresis and potential output: A post-KeynesianKaleckian agent-based approach, Economic Modelling, 52, 35-49.

Blume, L. E. \& Durlauf, S. N. (2006). The economy as an evolving complex system. III. current perspectives and future directions. New York: Oxford University Press.

Botte, F. (2014). Instability in a macroeconomic agent based model, filling the gap between micro and macro theories. Working Paper.www.boeckler.de/pdf/v_2014_10_30_botte. pdf

Bruun, C. (2007). Chapter XIV: Agent-based computational economics, In Rennard J. P. (ed.), Handbook of Research on Nature-Inspired Computing for Economics and Management. (pp. 183-197). Hershey: Idea Group Reference

Bruun, C. (2008). Rediscovering the economics of Keynes in an agent-based computational setting. Paper presented at Agent-Based Modeling in Economics and Finance, Trento, Italy.

Bruun, C. \& Heyn-Johnsen, C. (2009). The paradox of monetary profits: An obstacle to understanding financial and economic crisis?. Economics: The Open-Access, OpenAssessment, E-Journal, Discussion Paper, 52.

Bruun, C. (2010). The economics of Keynes in an almost stock-flow consistent agentbased setting. In Velupillai V. \& Zambelli, S. (eds.), Computable, constructive and behavioural economic dynamics: Essays in honour of Kumaraswamy, (pp. 442-461). London: Routledge.

Buchanan, M. (2008). This economy does not compute. The New York Times, October 1.

Canzian, G., Gaffeo, E. \& Tamborini, R. (2009). Keynes in the computer laboratory. An agentbased model with MEC, MPC, LP. In Hernandez C., Posada M. \& Lopez-Paradez A. (eds), Artificial Economics: The Generative Method in Economics, (pp. 15-28), Heidelberg: Springer.

Cogliano, J. F. \& Jiang, X. (2016). Agent-based computational economics: simulation tools for heterodox research. In Lee F. S. \& Cronin B. (eds), Handbook of Research Methods and Application in Heterodox Economics. Cheltenham: Edward Elgar.

David, N. (2013). Validating simulations. In Edmonds B. \& Meyer R. (eds), Simulating social complexity: A handbook. (pp. 135-171). Heidelberg: Springer.

Epstein, J. M. (2006a). Generative Social Science. New Jersey: Princeton University Press.

Epstein, J. M. (2006b). Remarks on the foundations of agent-based generative social science. In Tesfatsion L. \& Judd K. L. (eds). Handbook of computational economics, (pp. 15851604). 2: Agent-Based Computational Economics. Amsterdam: North-Holland. 
Farmer, J. D. \& Foley, D. (2009). The economy needs agent-based modelling. Nature, 460 (7256). 685-686.

Gaffard, J-L. \& Napoletano, M. (2012). Improving the toolbox: New advances in agent-based and computational models. In Gaffard J-L. \& Napoletano M. (eds). Agent-Based Models and Economic Policy, (pp. 7-13). Paris: OFCE. www.ofce.sciences-po.fr/pdf/revue/124/ revue-124.pdf.

Gilbert, N. \& Troitzsch, K. G. (2004). Simulation for the social sciences. Second Ed., New York: Open University Press.

Gilbert, N. (2008). Agent-based models. Los Angeles: Sage Publications.

Goodwin, R. M. (1967). A growth cycle'. In Feinstein C. H. (ed.), (pp. 54-58). Socialism, capitalism and economic growth: Essays presented to maurice dobb, Cambridge: Cambridge University Press.

Hasselman, K. (2010). Application of system dynamics to climate policy assessment. In Fitt A. D., Norbury J., Ockendon H. and Wilson E. (eds). (pp. 203-208). Progress in industrial mathematics at ECMI 2008. Heidelberg: Springer.

Janssen, M. (2012). Introduction to agent-based modeling. OpenABM - CoMSES Network. https://www.openabm.org/book/introduction-agent-based-modeling.

Lavoie, M. (2015). Post-Keynesian economics: New foundations. Cheltenham: Edward Elgar.

Lee, F. S. (2012). Heterodox economics and its critics. Review of Political Economy, 24 (2), 337-351.

Michell, J. (2014). A Steindlian account of the distribution of corporate profits and leverage: A stock-flow consistent macroeconomic model with agent-based microfoundations. The Post-Keynesian Economics Study Group. https://www.postkeynesian.net

Moore, B. J. (2006). Shaking the invisible hand: Complexity, endogenous money and exogenous interest rate. Hampshire: Palgrave Macmillan.

Moss, S. (2011). Agent based modeling and neoclassical economics: a critical perspective. In Meyers R. A. (ed.),(pp. 22-29). Complex systems in finance and econometrics, New York: Springer.

Radzicki, M. J. (2008). Institutional economics, post-Keynesian economics, and system dynamics: Three strands of a heterodox braid. In Harvey J. T. \& Garnett R. F. (eds),(pp. 156-184). Future Directions for Heterodox Economics. Ann Arbor, MI: The University of Michigan Press.

Reid, S. G. (2014). Agent-based computational economic models. Turing finance. Retrieved: January 13. From http://www.turingfinance.com/agent-based-computational-economicmodels/

Richiardi, M. G. (2012). Agent-based computational economics: a short introduction. The Knowledge Engineering Review, 27 (2),137-149.

Rosser, J. B. (2006). Complex dynamics and post Keynesian economics. In Setterfield M. (ed.). (pp. 74-98.). Complexity, endogenous money and macroeconomic theory, Cheltenham: Edward Elgar. 
Rosser, J. B. (2009). Theoretical and policy issues in complex Post Keynesian ecological economics. In Holt P. F., Pressman S. \& Spash C. L. (eds), (pp. 221-236.). Post Keynesian and ecological economics: Confronting environmental issues, Cheltenham: Edward Elgar.

Setterfield, M. \& Budd, A. (2011). A Keynes-Kalecki model of cyclical growth with agentbased features". In Arestis P. (ed.), (pp. 228-250). Microeconomics, macroeconomics and economic policy, Hampshire: Palgrave Macmillan.

The Economist (2010). Agents of change. Jul 22 nd.

Tesfatsion, L. (2016). Agent-based computational economics: Growing economies from the bottom up. Iowa State University, Ames, Iowa. From http://www2.econ.iastate.edu/ tesfatsi/ace.htm.

Tesfatsion, L. (2006). Agent-based computational economics: A constructive approach to economic theory. In Tesfatsion L. and Judd K. L. (eds), (pp. 831-880). Handbook of computational economics, 2: Agent-based computational economics, Amsterdam: North-Holland.

Thornton, T. (2014). The coming complexity revolution? Heterodoxy in economics: from history to pluralism J. E. King Conference, April 15-16, 2014, Victoria University, Melbourne. https://www.vu.edu.au/sites/default/files/cses/pdfs/ thornton-paper.pdf.

Wikipedia(a). Complex adaptive system. From https://en.wikipedia.org/wiki/Complex_ adaptive_system.

Wikipedia(b). Complex dynamics. From https://en.wikipedia.org/wiki/Complex_dynamics.

Wilensky, U. \& Rand, W. (2015). An introduction to agent-based modeling: Modeling natural, social and engineered complex systems with Netlogo. Cambridge, MA: The MIT Press.

Wilensky, U. (2011). Netlogo simple economy model. Center for Connected Learning and Computer-Based Modeling, Northwestern University, Evanston, IL. From http://ccl. northwestern.edu/netlogo/models/IABMTextbook/SimpleEconomy.

Wilensky, U. (2005). NetLogo wolf sheep predation (system dynamics) model. Center for Connected Learning and Computer-Based Modeling, Northwestern University, Evanston, IL. http://ccl.northwestern.edu/netlogo/models/ wolfsheeppredation(system dynamics).

Wilensky, U.(1997). Netlogo segregation model. Center for Connected Learning and ComputerBased Modeling, Northwestern University, Evanston, IL. http://ccl.northwestern.edu/ netlogo/models/segregation

Wilensky, U. (1999). NetLogo. Center for Connected Learning and Computer-Based Modeling, Northwestern University, Evanston, IL. http://ccl.northwestern. edu/netlogo/

https://www.postkeynesian.net/about/

http://www.complexityexplorer.org/explore/glossary. 
